\title{
DNA methylation similarities in genes of black South Africans with systemic lupus erythematosus and systemic sclerosis
}

Puleng Matatiele ${ }^{1}$, Mohamed Tikly ${ }^{2}$, Gareth Tarr $^{2}$ and Mary Gulumian ${ }^{1,3^{*}}$

\begin{abstract}
Background: Systemic lupus erythematosus (SLE) and systemic sclerosis (SSC) are systemic autoimmune connective tissue diseases that share overlapping clinico-pathological features. It is highly probable that there is an overlap in epigenetic landscapes of both diseases. This study aimed to identify similarities in DNA methylation changes in genes involved in SLE and SSc. Global DNA methylation and twelve genes selected on the basis of their involvement in inflammation, autoimmunity and/or fibrosis were analyzed using PCR arrays in three groups, each of 30 Black South Africans with SLE and SSC, plus 40 healthy control subjects.

Results: Global methylation in both diseases was significantly lower $(<25 \%)$ than in healthy subjects $(>30 \%, p=$ 0.0000001). In comparison to healthy controls, a similar gene-specific methylation pattern was observed in both SLE and SSC. Three genes, namely; PRF1, ITGAL and FOXP3 were consistently hypermethylated while CDKN2A and CD70 were hypomethylated in both diseases. The other genes (SOCS1, CTGF, THY1, CXCR4, MT1-G, FLI1, and DNMT1) were generally hypomethylated in SLE whereas they were neither hyper- nor hypo-methylated in SSC.

Conclusions: SSC and SLE patients have a higher global hypomethylation than healthy subjects with specific genes being hypomethylated and others hypermethylated. The majority of genes studied were hypomethylated in SLE compared to SSc. In addition to the commonly known hypomethylated genes in SLE and SSC, there are other hypomethylated genes (such as MT-1G and THY-1) that have not previously been investigated in SLE and SSc though are known to be hypermethylated in cancer.
\end{abstract}

Keywords: Methylation, Peripheral blood, Genomic DNA, Systemic lupus erythematosus, Systemic sclerosis, Autoimmunity, Methyl qPCR arrays

\section{Background}

Systemic lupus erythematosus (SLE, lupus) and systemic sclerosis (SSc, scleroderma) are both autoimmune connective tissue diseases associated with autoantibody production. In SLE, inflammation often affecting more than one organ is the outstanding pathological feature [1], whereas in SSc immune activation results mainly in fibrosis of the skin and internal organs, and damage of small blood vessels [2,3]. Although the exact genetic

\footnotetext{
*Correspondence: mary.gulumian@nioh.nhls.ac.za

'Toxicology \& Biochemistry Research Section, National Institute for

Occupational Health, National Health Laboratory Service, Johannesburg, South Africa

${ }^{3}$ Division of Molecular Medicine and Haematology, School of Pathology, Faculty of Health Sciences, University of the Witwatersrand, Johannesburg, South Africa

Full list of author information is available at the end of the article
}

causes of both SSc and SLE are still unknown, the environmental influence reflected by the epigenetic mechanisms, with DNA methylation changes in particular, are generally considered as key players in the onset and progression of both diseases $[1,4,5]$. The concordance of these conditions in monozygotic twins indicates that epigenetic factors, mediated by environmental factors, may have a role to play $[4,6,7]$.

Epigenetic mechanisms, one example of which is DNA methylation, are vital for the development and function of the immune system. DNA methylation is important in the regulation of inflammatory genes [8]. Hypermethylation of promoter regions of genes is typically associated with transcriptional silencing while hypomethylation facilitates gene expression. In autoimmunity, aberrant DNA methylation profiles in genes encoding metalloproteinases, 
proinflammatory cytokines and chemokines, all processes that regulate inflammation have been reported. Although the roles and interactions of abnormal DNA methylation in relation to inflammation and immunity are not yet clear, evidence suggests that key mediators of inflammation-induced DNA methylation changes are oxidative stress and the increased pro-inflammatory cytokines [9]. Endogenous triggers such as antigens released from dying cells are recognized as the main stimulus to abnormal production of type I interferon (IFN-I) resulting in chronic inflammation in SLE and SSc, and perhaps other autoimmune diseases [10]. The clearance of apoptotic cells is impaired in SLE and SSc, providing a potential continuous source of endogenous antigen. Proper control of DNA methylation is maintained by the DNA methyltransferases (DNMTs), and it appears that persistent exposure to pro-inflammatory cytokines can contribute to DNA hypomethylation through decreased expression of DNA methyltransferase (DNMT) $[9,11]$. On the other hand, overexpression of the de novo methyltransferases is implicated in the establishment of gene-specific hypermethylation [12-14]. An illustration as to how methylation of gene promoters by DNMT1 leads to gene silencing, while its inhibition leads to hypomethylation is shown in Fig. 1.

Accumulating evidence indicates that abnormal DNA hypomethylation and expression of methylation-related genes in CD4+ $\mathrm{T}$ cells are an important epigenetic hallmark associated with SLE and SSc [15-17]. This is accounted for by the fact that DNMT1 expression and enzymatic activity is reduced in SLE and SSc, and given the high prevalence of inflammation and oxidative stress in both conditions $[9,15]$. Several classic methylation- sensitive autoimmunity-related genes in SLE and SSc have been identified that include CD11a (ITGAL), perforin (PRF1), CD70 (TNFSF7), CD40 ligand (TNFSF5) and $P P 2 A c \alpha$ [5,18]. Other top-ranked methylation-sensitive autoimmunity-related genes known to be associated with SSc include CTGF, FLI1 and DNMT [19,20]. In fact, current epigenetic studies reveal a growing list of genes dysregulated by altered DNA methylation in many autoimmune diseases. The array of genes dysregulated by altered DNA methylation thus provides an opportunity to examine the patterns of inactivation of such genes among different autoimmune diseases.

The aim of this study was to determine global DNA methylation and gene-specific methylation of potentially "overlapping" genes involved in either collagen synthesis, the inflammatory response or tumour suppression, in black African SLE and SSc patients using genomic DNA from whole blood. The choice of whole blood over CD4+ $\mathrm{T}$ cells as study material in this work was based on the consideration that SLE and SSc display many abnormalities across all arms of the immune system, represented in whole blood. In fact, SLE and SSc therapies attempting to target specific components of the immune system have so far not been successful, so much that broad-based immunosuppression still remains the mainstay in the treatment of both conditions [21]. Also, it has been confirmed that defects in epigenetic regulation of both CD4+ T cells [22,23] and B-cells [24-26] are involved in both SLE and SSc. Moreover, literature indicates that the total number of $\mathrm{B}$ and $\mathrm{T}$ lymphocytes is significantly reduced in SLE and SSc $[27,28]$, a situation that is aggravated by the immunosuppression therapy. It has therefore become clear that the global methylation landscape in these two diseases

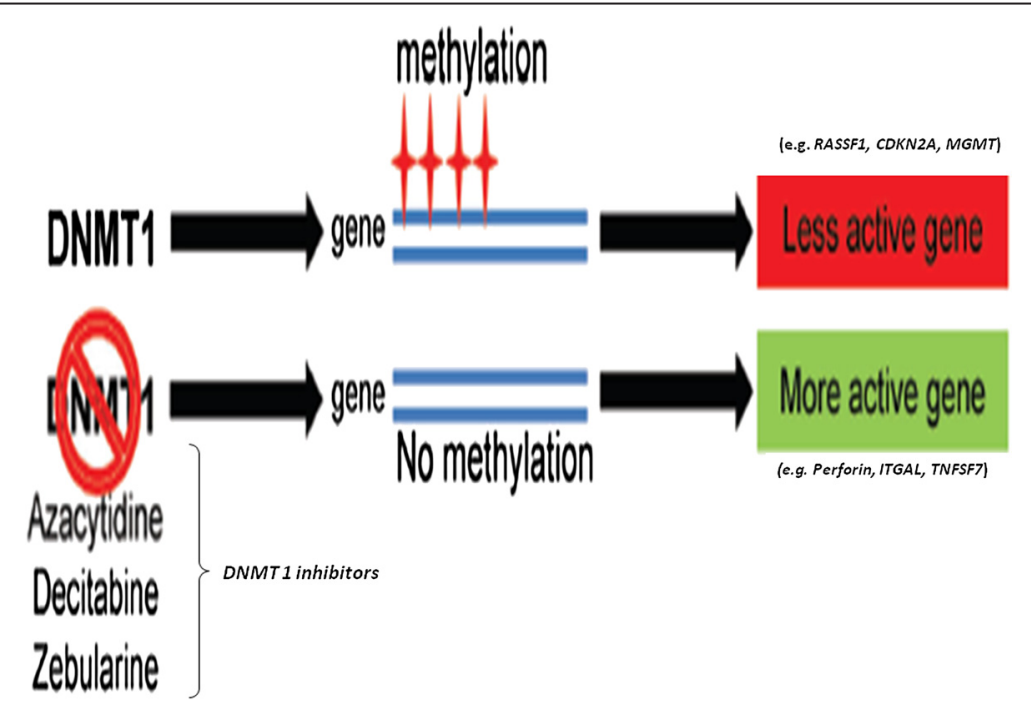

Fig. 1 Short title: Role of DNMT1 in DNA methylation. Long title: Methylation of gene promoters by DNMT1 leads to gene silencing, while its inhibition leads to hypomethylation. Modified from Zielske, [66] 
involves both $\mathrm{T}$ and $\mathrm{B}$ lymphocytes, hence the choice to study global DNA methylation as opposed to methylation of only CD4+ T cells as in many other studies. Also, the great majority of patients in this study had been receiving glucocorticoids and immunosuppressants at different doses, and therefore it would have been unethical and not practically viable to collect enough blood from them to be able to study individual lymphocyte populations, hence the use of whole blood.

\section{Results}

The clinical information for the study participants is presented in Tables 1 and 2. The records of all SLE and SSc patients enrolled in the study were retrospectively reviewed. In the case of SLE, patients' disease-related symptoms reflecting disease severity such as skin and musculoskeletal involvement, serositis, systemic vasculitis and kidney involvement were identified. The data showed that these SLE patients fell into three phenotypic subsets as follows; $30 \%$ (7 of 30) made SLE1 group (skin and musculoskeletal involvement); 57 \% (17/30) formed SLE2 (serositis, systemic vasculitis, with no kidney involvement) and $13 \%$ (4/30) made up SLE3 group (glomerulonephritis). All SSc patients had positive antinuclear autoantibodies (ANA) but only a few were positive for anti-centromere autoantibodies (ACA) and/or anti-topoisomerase antibodies (ATA). The SLEDAI score showed that SLE was either mild or moderate, with no severe cases of the condition in the study group. In addition, correlation of PGA score (not shown), SLEDAI and methylation status, showed that the sicker the patient (increasing SLEDAI and PGA score), the greater was the percentage of global hypomethylation as well as more number of genes demethylated. The majority $(67 \%, 20 / 30)$ of SLE patients also had discoid lupus erythematosus (DLE), while $50 \%$ of them tested positive for the Coomb's test.

The SSc and SLE groups exhibited significantly lower global methylation levels, compared to the control group $(\mathrm{p}<0.000001)$ (Fig. 2). This is so despite the fact that global hypomethylation was also observed even among some of the healthy subjects. Further analysis of the individual genes, as shown in the heat map (Fig. 3), indicates that the majority of genes included in the present study were hypomethylated in the patient groups [9 of $12(75 \%)$ of genes] compared to the control group.
Conversely, three genes were hypermethylated in the patient groups, namely; PRF1, ITGAL and FOXP3. When comparing the two patient groups to each other a significantly differential methylation pattern was observed amongst the individual genes with the exception of ITGAL and PRF1 which were consistently hypermethylated in both diseases while $C D K N 2 A$ and $C D 70$ were consistently hypomethylated. Fig. 3 also shows a uniform methylation distribution among SLE patients, whereas SSc patients seem to split into several groups, which could perhaps indicate the different disease grades. All the other genes analyzed (SOCS1, CTGF, THY1, CXCR4, MT1-G, FLI1, and DNMT1) were generally hypomethylated in SLE whereas they were neither hypermethylated nor hypomethylated in most SSc patients.

\section{Discussion}

Our findings confirm that DNA methylation is globally reduced in SLE and SSc, and that there is abnormal expression of methylation-related genes [15]. Also, increasing SLEDAI and PGA scores were indicative of increasing number of genes demethylated in SLE and worsening of the disease in the patient. In SSc there was no difference observed in both global and gene-specific DNA methylation between diffuse and limited sclerosis patients, even though subset-specific DNA methylation abnormalities have been reported between the two disease subtypes [29]. In fact both were equally hypomethylated (about $18 \%$ DNA methylation). This highlights the robustness of genome-wide analyses over analysis of a few candidate genes in this study. Global hypomethylation was also observed even among some of the healthy subjects (Fig. 2). An important factor to consider in this situation is the well known fact that there are differences in methylation status of individuals which is to some extent controlled by certain host and lifestyle characteristics such as age, smoking, alcohol drinking, diet and health history [30-32]. These factors were controlled to a very limited extend in this study. Fig. 3 also shows that there are some patients that fall within both SLE and SSc groups. Serology tests (ANA positivity) also confirm overlap in both conditions (Table 3). This is not surprising since it is known that both SSc and SLE show an overlap of symptoms and in many instances there are patients who develop both conditions $[17,33]$.

Table 1 Demographics for study participants

\begin{tabular}{|c|c|c|c|c|c|c|}
\hline \multirow[t]{2}{*}{ Study subjects } & \multicolumn{2}{|c|}{ Controls } & \multicolumn{2}{|c|}{ SLE } & \multicolumn{2}{|c|}{ SSC } \\
\hline & $\mathrm{n}$ & Age range (mean) yrs & $n$ & Age range (mean) yrs & $\bar{n}$ & Age range (mean) yrs \\
\hline Male & 12 & $20-51(35)$ & 5 & $22-66(45)$ & 3 & $48-56(51)$ \\
\hline Female & 28 & $22-53(36)$ & 25 & $22-63(42)$ & 27 & $32-60(47)$ \\
\hline Total & 40 & $20-53(38)$ & 30 & $22-66(42)$ & 30 & $32-60(48)$ \\
\hline
\end{tabular}


Table 2 Lupus and scleroderma disease presentation according to autoantibody serology, manifestations and tests

\begin{tabular}{|c|c|c|c|c|c|c|c|c|c|}
\hline \multirow{2}{*}{\multicolumn{5}{|c|}{$\begin{array}{l}\text { Systemic Lupus Erythematosus (SLE) } \\
(\mathrm{n}=30)\end{array}$}} & \multirow{2}{*}{\multicolumn{5}{|c|}{$\begin{array}{l}\text { Systemic Sclerosis (SSc) } \\
(\mathrm{n}=30)\end{array}$}} \\
\hline & & & & & & & & & \\
\hline \multirow[t]{2}{*}{$\begin{array}{l}\text { Autoantibodies, } \\
\text { manifestations } \\
\text { and tests }\end{array}$} & SLEDAI scor & & & & $\begin{array}{l}\text { Autoantibodies } \\
\text { and } \\
\text { manifestations }\end{array}$ & $\begin{array}{l}\text { dcSSC } \\
(n=14)\end{array}$ & $\begin{array}{l}\text { ICSSC } \\
(n=5)\end{array}$ & $\begin{array}{l}\text { "other" (e.g. UCTD, } \\
\text { morphea, Reynaud's) } \\
(n=3)\end{array}$ & $\begin{array}{l}\text { Unclassified } \\
(n=7)\end{array}$ \\
\hline & $\begin{array}{l}\text { Mild, score } \\
<10(n=21)\end{array}$ & $\begin{array}{l}\text { Moderate, score } \\
10-20(n=3)\end{array}$ & $\begin{array}{l}\text { Severe, score } \\
>20(n=0)\end{array}$ & $\begin{array}{l}\text { unscored } \\
(n=6)\end{array}$ & $\begin{array}{l}\text { ANA positive } \\
(n=22) 73 \%\end{array}$ & 13 & 6 & 5 & $\mathrm{n} / \mathrm{a}$ \\
\hline $\begin{array}{l}\text { ANA positive } \\
(n=29) 97 \%\end{array}$ & 20 & 3 & 0 & 6 & $\begin{array}{l}\text { ACA positive } \\
(n=6) 20 \%\end{array}$ & 3 & 2 & 1 & $\mathrm{n} / \mathrm{a}$ \\
\hline $\begin{array}{l}\text { DLE positive } \\
(n=19) 63 \%\end{array}$ & 15 & 2 & 0 & 3 & $\begin{array}{l}\text { ATA positive } \\
(n=2) 7 \%\end{array}$ & 2 & 0 & 0 & $\mathrm{n} / \mathrm{a}$ \\
\hline $\begin{array}{l}\text { Coombs' test } \\
\text { positive } \\
(n=14) 47 \%\end{array}$ & 9 & 3 & 0 & 3 & $\begin{array}{l}\text { ILD }(n=10) \\
33 \%\end{array}$ & 6 & 1 & 3 & $\mathrm{n} / \mathrm{a}$ \\
\hline
\end{tabular}

Abbreviations: ACA, anticentromere autoantibody; ANA, anti-nuclear antibodies; ATA, Antitopoisomerase antibodies; Coombs' test, detects presence of antibodies that act against the surface of red blood cells, indicates haemolytic anaemia; DLE, Discoid lupus erythematosus; ILD, interstitial lung disease, indicator of direct pulmonary involvement, and leading cause of death; dcSSC, diffuse cutaneous systemic sclerosis; ICSSC, limited cutaneous systemic sclerosis; UCTD, undifferentiated connective tissue disease; SLEDAl, Systemic Lupus Erythematosus Disease Activity Index; $n / a$, results not available.

In this study specific genes that were found to be hypomethylated include CTGF, CXCR4, CD70, MT-1G, THY1, CDKN2A, SOCS1, FLI1 and DNMT1. CTGF is known to be constitutively upregulated in SSc and has been hypothesized to be a key mediator of pulmonary fibrosis due to its overexpression which correlates well with severity of lung fibrosis frequently observed in this disease [12]. Therefore, the observed CTGF hypomethylation in this study could well indicate the progression of both SLE and SSc to a stage of pulmonary involvement. In fact, the indication of pulmonary involvement, which is the presence of interstitial lung disease (ILD), was observed in $17 \%(5 / 30)$ of the SSc patients. CXCR4 has been found prominently, particularly in various leukocyte subsets of the skin and kidney of SLE patients, and has been shown to mediate chemotaxis of T-lymphocytes [34]. Hypomethylation of this gene in the study could also indicate its overexpression and hence progression of disease in these patients.

Hypermethylation results in suppression of PRF1, $I T G A \mathrm{~L}$ and FOXP3 and this explains why these three genes may have a role in the immunopathogenesis of

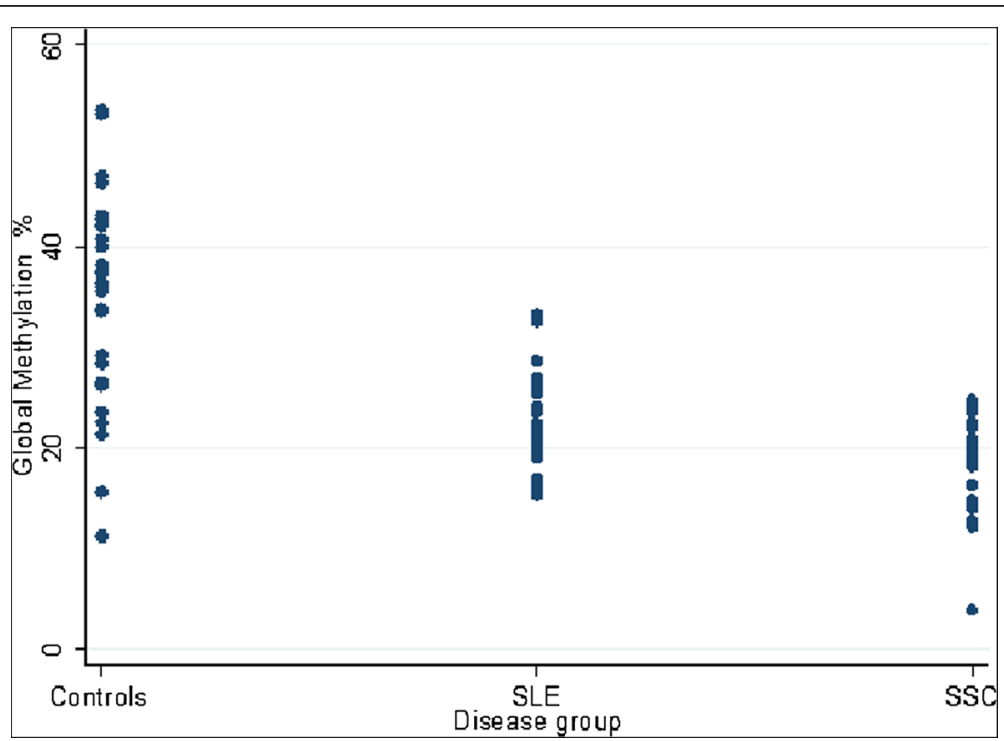

Fig. 2 Short title: Global methylation in peripheral blood of SLE, SSC and healthy (C) subjects. A significant difference in global methylation between the study groups is indicated by the p-values. Long Title: Analysis of global methylation levels in peripheral blood of SLE, SSC and healthy control subjects (triplicate measurements). The dot plot shows a significant difference in global methylation between the patients and healthy subjects, which is also indicated by the p-values. However, SLE and SSC patients were not significantly different from each other although there was a trend towards lower values in the SSC group compared to the SLE group 


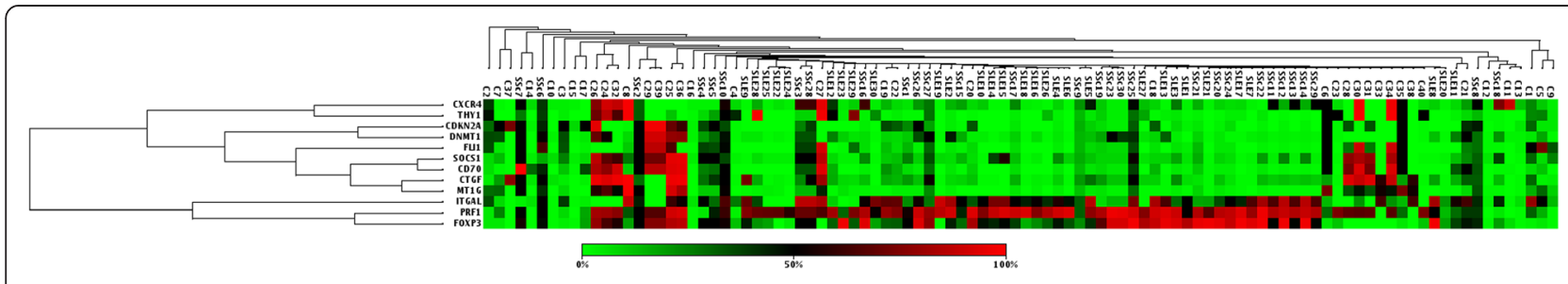

Fig. 3 Short title: Comparison of gene-specific methylation in lupus (SLE), scleroderma (SSC) and healthy subjects (C). Long title: Heat map showing distribution of methylation among the 12 genes analyzed in lupus (SLE) and scleroderma (SSC) patients in comparison to healthy controls (C)

SSc and SLE. For example, it has been demonstrated that the epigenetic control of FOXP3 for effective function of T-regulatory cells dictates the requirement of a hypomethylated FOXP3 promoter [35]. However, the opposite is seen in the case of these SLE and SSc patients, and this situation is known to correlate highly with parameters of disease severity and the high incidence of SLE and SSc and other autoimmune diseases.

Many studies report hypomethylation in promoter regions of PRF1 and ITGAL with consequent overexpression of these genes in SLE. It is therefore tempting to attribute the observed hypermethylation of these two genes in this study to technical/experimental errors. However, further survey of literature indicates that there are high levels of free polyamines in SLE and that polyamines not only cause SLE, but they are also important in sustaining the disease [36,37]. These increased polyamine concentrations result in enhanced methylation of the ITGAL promoter and increased DNMT1 activity [38]. Hypermethylation of the ITGAL promoter region has also been observed in CD4+ T cells from other autoimmune diseases [39]. So, we suggest that even though hypomethylated ITGAL and PRF1 promoters are mostly

Table 3 Analysis of variance was conducted on the global methylation results with disease group as the factor variable, and the results were verified with Bartlett's test. A Bonferroni correction shows that the SLE and SSc groups were significantly different from the controls but not significantly different from each other, although there was a trend towards lower values in the SSC group compared to the SLE group

\begin{tabular}{|c|c|c|c|}
\hline \multirow{2}{*}{$\begin{array}{l}\text { Study } \\
\text { groups }\end{array}$} & \multicolumn{3}{|c|}{ Global methylation \% } \\
\hline & Mean & Standard deviation (SD) & Range \\
\hline Controls & 33.9 & 11 & $11-53$ \\
\hline SLE & 22.2 & 5 & $15-33$ \\
\hline SSC & 17.7 & 5 & $3.8-24$ \\
\hline
\end{tabular}
comparison

(mean difference) $P$ value

Controls SLE

SLE $\quad(-11) p=0.00$

SSc $\quad(-16) p=0.00 \quad(-4) p=0.068$ reported as characteristic of SLE, this is not always the case as was seen in this study, and this situation may represent the co-occurrence of other autoimmune conditions such as diabetes and cancer, with SLE and SSc. The opposite from what is reported in other studies is also observed for several of these genes in this study. For example, hypermethylation of both FLI1 in SSc and SOCS1 in SLE was not observed in our study even though hypermethylation of promoter regions of both genes has been previously implicated in the pathophysiology of SSc and SLE, respectively [40-42]. However, FLI-1 overexpression, probably as a result of promoter hypomethylation, has been detected in various types of cancer and other diseases [43]. Most importantly, it has been reported that in lupus-prone mice Fli1 expression fails to become down-regulated likely due to aberrant transcriptional regulation [44]. Also, it is reported that increasing SOCS1 expression by cells may be useful as a strategy to block CD8(+) T cell-mediated autoimmunity and to more generally prevent cytokine-dependent tissue destruction in inflammatory diseases [45]. The observed hypomethylation of FLI1 and SOCS1 could therefore imply that both genes were overexpressed in these patients for the reasons already mentioned. Similarly, other studies have reported that CDKN2A and DNMT1 gene promoters are hypermethylated in DNA derived from plasma and blood cells of patients with SLE, whereas the opposite was observed in this study [46,47]. Increased expression of $C D K N 2 A$ has been shown to be as a result of promoter demethylation [48,49] and recently it has been shown that presence of up-regulated $C D K N 2 A$ expression, promotes apoptosis and cellular senescence of bone marrow-derived mesenchymal stem cells observed in SLE patients [50]. In the same way, Liu et al., [51] reported that expression of DNMT1 mRNA was significantly increased in SLE, whereas other studies [52] describe the opposite. As mentioned above high levels of natural polyamines in SLE result in increased DNMT1 activity, and this is probably due to a hypomethylated promoter region as was observed in this study.

The other genes (MT-1G and THY1) which were found to be hypomethylated in this study have not been previously investigated in SSc and SLE, though are 
known to be hypermethylated in cancer $[16,53,54]$. Finally, there are significant methylation differences in individual genes between the two patient groups, and though the methylation status of some may not conform to the majority of literature reports this does not defy what is already known about the role of these genes in SLE and SSc, which is their involvement in inflammation, autoimmunity and/or fibrosis. Moreover, Wiley et al., [55] suggest that variation in epigenetic changes may play a critical role in the different manifestations of the disease observed among ethnic groups. Kozłowska et al., [56] also suggest that exposure to unique environmental factors as well as genetic variation associated with the special racial properties of the examined groups both contributing to SLE and SSc in this population could have resulted in these deviations. It would be interesting to investigate the influence of ethnicity and/or race on the epigenetics of these genes to complete our study [57]. Hughes and Sawalha [58] suggest that the fact that patients experience periods of calm punctuated by disease flare-ups in SLE and SSc is as a result of epigenetic states which vary with time and between cell types, and if this is the case these results could be highly influenced by the disease activity state at the time of sampling. It should also be noted that since blood samples were collected only once, at commencement of the study, it was not possible to determine the effect of immunosuppressive treatment on methylation in the study subjects. As a result, neither global DNA hypomethylation nor changes in gene-specific DNA methylation patterns were accounted for by the type of medication the patients were taking. However, certain studies have reported that the antiproliferative drugs commonly used to treat SLE do not have any effect on DNA methylation [59-61], and therefore it is believed that changes in the methylation status of these patients are unlikely to be the result of immunosuppressive treatment. On the other hand, other studies show that systemic steroid use is associated with variable DNA methylation patterns throughout the genome $[23,62]$, which could have been missed due to the limited number of genes investigated in this study.

Due to the small number of genes analysed it was not possible to neither reliably distinguish SSc from SLE, nor clearly indicate the overlap genes. It should also be noted that inconsistencies in literature on methylation/ disease relationship are often attributable to the measurement method; hence the need for standardization of methods for DNA methylation analysis if further studies are undertaken. Therefore, one could say that the current data strongly demonstrate the need for investigation on a larger scale, with many subjects and many genes as is possible with the use of microarrays in genome-wide association studies. May be these epigenetic changes can be used as biomarkers of these diseases or their severity. It is also worth noting that the overall picture regarding epigenetic control of autoimmunity still remains elusive. However, evidence points to metabolic control as the central mechanism underlying aberrant gene expression leading to dysregulation of the immune system, especially in SLE [63]. Apparently mitochondrial dysfunction in $\mathrm{T}$ cells as a result of oxidative stress is the driver of chronic inflammation which in turn triggers autoimmunity in SLE. It is therefore possible that the metabolic profile could actually be the determining factor with regard to the differences between the different autoimmune diseases and their variations, as well as between the healthy and the sick.

\section{Conclusion}

Notwithstanding the limitations of the study, this work confirms that SSc and SLE patients have a higher global hypomethylation than healthy subjects. As far as the authors are aware, this is the first report of a comparison of DNA methylation of genes affected in both SLE and SSc. Even though it is generally accepted that in addition to genetic dysregulation epigenetic modification of genes is responsible for both diseases the origin of epigenetic similarity of their symptoms has never been investigated. Moreover, this is the first study in which DNA methylation analysis of SLE and SSc has been done in the black African population. The study has shown that in addition to the commonly known hypomethylated genes in SLE and SSc, there are other hypomethylated genes that have not previously been investigated in both conditions, even though they are known to be hypermethylated in cancer. These genes are involved in either collagen synthesis, inflammatory response or have tumour suppressor activities, and their dysregulation could contribute to inflammation/ fibrosis/tumourigenesis processes characteristic of SLE and SSc. It is obvious that there are several emergent phenotypes in SLE and SSc, likely as a result of their interaction over time which may in turn be influenced by cooccurrence with other diseases, unique environmental exposures or ethnicity/race, and it is not as yet possible to understand clearly delineation of these various components. Perhaps, it is more studies like this that could lead to identification of critical genes common to both SLE and SSc, which could possibly enable researchers to elucidate the aetiology of both diseases and to design appropriate gene targeted therapy.

\section{Methods}

\section{Patients}

This study was approved by the Ethics Committee for Research on Human Subjects of both the University of the Witwatersrand (Johannesburg, South Africa) and the South African National Blood Transfusion Services (SANBS). A total of 100 adult Black South African 
participants (18 years or older) comprising 30 patients each of SLE and SSc, and 40 healthy controls were recruited for the study. These SSc and SLE patients each fulfilling the American College of Rheumatology (ACR) criteria for SSc or SLE $[64,65]$ were recruited from the Connective Tissue Diseases Clinic, Chris Hani-Baragwanath Hospital (Johannesburg, South Africa). The healthy individuals were volunteer blood donors recruited during a blood drive by the SANBS (Johannesburg, South Africa).

\section{Serology tests and disease activity}

All patients underwent baseline investigations for haematological and biochemical parameters, chest radiograph and electrocardiogram. Autoantibodies (e.g. ANA, antidsDNA, ATA) were detected by indirect immunofluorescence test. Various manifestations were categorized after detailed clinical examination and laboratory investigations (Table 3). Disease activity was assessed by the physician global assessment (PGA) score as well as the SLE Disease Activity Index (SLEDAI).

\section{Sample collection and DNA preparation}

After obtaining written informed consent from all blood donors, $5 \mathrm{ml}$ samples of peripheral blood were collected in EDTA tubes. Genomic DNA (gDNA) from whole blood was isolated using GenElute mammalian DNA extraction kit (Sigma-Aldrich, catalogue no. G1N70). The isolated DNA was quantified using the Nanodrop 2000C spectrophotometer (Thermoscientific) and thereafter stored at $-20{ }^{\circ} \mathrm{C}$ until use.

\section{Quantification of global DNA methylation}

Imprint $^{\text {ti }}$ Methylated DNA kit (Sigma-Aldrich, catalogue No. MDQ1) was used to determine global DNA methylation shifts and triplicate values were measured. This is an ELISA-based procedure consisting of four steps. Up to $200 \mathrm{ng}$ of purified DNA is bound to the wells of the assay strip. The methylated DNA is detected using the capture and detection antibodies, and then quantified colorimetrically. The amount of methylated DNA present in the sample is proportional to the absorbance measured and is expressed as a percentage of the provided DNA control.

\section{Gene-specific DNA methylation analysis}

The panel of genes profiled consisted of twelve genes, namely; ITGAL, PRF1, SOCS1, CTGF, CXCR4, THY1, MT1G, FLI1, P16 ${ }^{I N K 4}$, DNMT1, FOXP3, and CD70. PCR Array analysis was performed using the EpiTect Methyl PCR Arrays technology (SABiosciences) on a 7300 Applied Biosystems real-time PCR instrument.

\section{Data analysis}

The methylation qPCR Arrays data was analyzed using an integrated Excel-based template provided by the
Methyl Screen ${ }^{\mathrm{m}}$ technology (SABiosciences). The template automatically performs all $\Delta \mathrm{Ct}$ based calculations from the raw threshold cycle $(\mathrm{Ct})$ values to determine gene specific DNA methylation status, and then normalizes the $\mathrm{Ct}$ values of both digests with the mock digestion values to calculate and report the percentage of the DNA that is methylated and unmethylated.

\section{Statistical analysis}

The methylation results data was captured in standard data entry software STATA ${ }^{\circ}$. Analysis was carried out using both Kruskal Wallis test and Mann-Whitney $U$-test. Analysis of variance was conducted and Bartlett's test was used to confirm observed variances. A Bonferroni correction was used to compare the individual groups. $\mathrm{P}$ values were generated from individual $\mathrm{t}$-tests and differences were considered significant at a $\mathrm{p}$ value $<0.05$.

\section{Abbreviations \\ DNA: Deoxyribonucleic acid; ELISA: Enzyme-linked immunosorbent assay; EDTA: Ethylenediaminetetraacetic acid; gDNA: Genomic DNA; PCR: Polymerase chain reaction; SANBS: South African National Blood Transfusion Services; SLE: Systemic lupus erythematosus; SSc: Systemic sclerosis; ACA: Anticentromere autoantibody; ANA: Anti-nuclear antibodies; ATA: Antitopoisomerase antibodies; DLE: Discoid lupus erythematosus; ILD: Interstitial lung disease; dcSSC: Diffuse cutaneous systemic sclerosis; ICSSC: Limited cutaneous systemic sclerosis; UCTD: Undifferentiated connective tissue disease; SLEDAI: Systemic Lupus Erythematosus Disease Activity Index; PGA: Physician Global Assessment.}

\section{Competing interests}

The authors declare that they have no competing interests.

\section{Authors' contributions}

PM conceived the study design, recruited study participants, participated in the data collection, data analysis/interpretation and wrote the manuscript. MT performed patient selection, blood sample collection, data analysis/ interpretation and revised the manuscript. GT performed patient selection and blood sample collection. MG conceived the study design, contributed to data analysis/interpretation and revised the manuscript. All authors read and approved the final manuscript.

\section{Acknowledgments}

The authors would like to thank the National Health Laboratory Service Research Trust (South Africa) for funding this study (study no. 94196). We greatly acknowledge Professor Michèle Ramsay for reviewing this work and Ms Kerry Wilson for her assistance with statistical analysis. We would like to also thank the many lupus, scleroderma and healthy participants for their contribution to our research.

\section{Author details}

${ }^{1}$ Toxicology \& Biochemistry Research Section, National Institute for Occupational Health, National Health Laboratory Service, Johannesburg, South Africa. ${ }^{2}$ Division of Rheumatology, Faculty of Health Sciences, University of the Witwatersrand, Johannesburg, South Africa. ${ }^{3}$ Division of Molecular Medicine and Haematology, School of Pathology, Faculty of Health Sciences, University of the Witwatersrand, Johannesburg, South Africa.

Received: 5 February 2015 Accepted: 1 May 2015

Published online: 20 May 2015

\section{References}

1. Ballestar E, Esteller M, Richardson BC. The epigenetic face of systemic lupus erythematosus. J Immunol. 2006;176(12):7143-7.

2. Abraham DJ, Varga J. Scleroderma: from cell and molecular mechanisms to disease models. Trends Immunol. 2005;26(11):587-95. 
3. Fleming JN, Schwartz SM. The pathology of scleroderma vascular disease. Rheum Dis Clin North Am. 2008;34(1):41-55.

4. Zwijnenburg PJG, Meijers-Heijboer H, Boomsma DI. Identical but not the same: the value of discordant monozygotic twins in genetic research. Am J Med Genet B Neuropsychiatr Genet. 2010;153B(6):1134-49.

5. Agarwal SK. The genetics of systemic sclerosis. Discov Med. 2010;10(51):134-43.

6. Javierre BM, Fernandez AF, Richter J, Al-Shahrour F, Martin-Subero Jl, RodriguezUbreva J, et al. Changes in the pattern of DNA methylation associate with twin discordance in systemic lupus erythematosus. Genome Res. 2010;20:170-9.

7. Ballestar E. Epigenetics lessons from twins: prospects for autoimmune disease. Clin Rev Allergy Immunol. 2010;39(1):30-41.

8. Yasmin R, Siraj S, Hassan A, Khan AR, Abbasi R, Ahmad N. Epigenetic regulation of inflammatory cytokines and associated genes in human malignancies. Mediators Inflamm. 2015;2015:8.

9. Perl A. Oxidative stress in the pathology and treatment of systemic lupus erythematosus. Nat Rev Rheumatol. 2013;9(11):674-86.

10. Gaipl US, Franz S, Voll RE, Sheriff A, Kalden JR, Herrmann M. Defects in the disposal of dying cells lead to autoimmunity. Curr Rheumatol Rep. 2004;6(6):401-7.

11. Balada E, Ordi-Ros J, Serrano-Acedo S, Martinez-Lostao L, Rosa-Leyva M, Vilardell-Tarrés M. Transcript levels of DNA methyltransferases DNMT1, DNMT3A and DNMT3B in CD4+ T cells from patients with systemic lupus erythematosus. Immunology. 2008;124(3):339-47.

12. Kikuchi R, Tsuda H, Kanai Y, Kasamatsu T, Sengoku K, Hirohashi S, et al. Promoter hypermethylation contributes to frequent inactivation of a putative conditional tumor suppressor gene connective tissue growth factor in ovarian cancer. Cancer Res. 2007;67(15):7095-105.

13. Vélez G, Rodríguez FM, Rodríguez JM. Subexpression of SOCS1 and constitutive activation of IFNA receptor associated proteins in systemic lupus erythematosus. Int Immunol. 2010;22(Suppl 1 Pt 1):i110-i8.

14. Li A, Li YM, Yang AZ, Yao X, Chen ZQ. Phenomena and pathological significances of the methylated p16 promotor in DNA derived from plasma and blood cells of patients with systemic lupus erythematosus. Zhongguo Yi Xue Ke Xue Yuan Xue Bao. 2006;28(5):675-81.

15. Lei W, Luo Y, Lei W, Luo Y, Yan K, Zhao S, et al. Abnormal DNA methylation in CD4+ T cells from patients with systemic lupus erythematosus, systemic sclerosis, and dermatomyositis. Scand J Rheumatol. 2009;38(5):369-74.

16. Balada E, Ordi-Ros J, Vilardell-Tarrés M. DNA methylation and systemic lupus erythematosus. Ann N Y Acad Sci. 2007;1108(1):127-136.

17. Higgs BW, Liu Z, White B, Zhu W, White WI, Morehouse C, et al. Patients with systemic lupus erythematosus, myositis, rheumatoid arthritis and scleroderma share activation of a common type I interferon pathway. Ann Rheum Dis. 2011;70(7):2029-36.

18. Assassi S, Mayes MD, Arnett FC, Gourh P, Agarwal SK, McNearney TA, et al. Systemic sclerosis and lupus: points in an interferon-mediated continuum. Arthritis Rheum. 2010;62(2):589-98.

19. Asano Y, Stawski L, Hant F, Highland K, Silver R, Szalai G, et al. Endothelial Fli1 deficiency impairs vascular homeostasis: a role in scleroderma vasculopathy. Am J Pathol. 2010;176(4):1983-98.

20. Asano Y, Bujor AM, Trojanowska M. The impact of Fli1 deficiency on the pathogenesis of systemic sclerosis. J Derm Sci. 2010;59(3):153-62.

21. Lo MS, Tsokos GC. T Cells in Systemic Lupus Erythematosus; progress toward targeted therapy. Rheumatologist, August 01, 2011. http://www.therheumatologist.org/details/print/1311659/August_2011.html. Accessed 11 May 2015.

22. Absher DM, Li X, Waite LL, Gibson A, Roberts K, Edberg J, et al. Genomewide DNA methylation analysis of systemic lupus erythematosus reveals persistent hypomethylation of interferon genes and compositional changes to CD4+ T-cell populations. PLoS Genet. 2013;9(8):e1003678.

23. Jeffries MA, Dozmorov M, Tang Y, Merrill JT, Wren JD, Sawalha AH. Genomewide DNA methylation patterns in CD4(+) T cells from patients with systemic lupus erythematosus. Epigenetics. 2011;6(5):593-601.

24. Zouali M. The epigenetic landscape of B lymphocyte tolerance to self. FEBS Lett. 2013;587(13):2067-73.

25. Wang Y, Yang Y, Luo Y, Yin Y, Wang Q, Li Y, et al. Aberrant histone modification in peripheral blood B cells from patients with systemic sclerosis. Clin Immunol. 2013;149(1):46-54.

26. Lai AY, Mav D, Shah R, Grimm SA, Phadke D, Hatzi K, et al. DNA methylation profiling in human $B$ cells reveals immune regulatory elements and epigenetic plasticity at Alu elements during B-cell activation. Genome Res. 2013;23(12):2030-41.
27. Scheinberg MA, Cathcart ES. B cell and T cell lymphopenia in systemic lupus erythematosus. Cell Immunol. 1974;12(2):309-14.

28. Horwitz D, Juul-Nielsen K. Human blood L lymphocytes in patients with active systemic lupus erythematosus, rheumatoid arthritis and scleroderma: a comparison with T and B cells. Clin Exp Immunol. 1977;30(3):370.

29. Altorok N, Tsou P-S, Coit P, Khanna D, Sawalha AH. Genome-wide DNA methylation analysis in dermal fibroblasts from patients with diffuse and limited systemic sclerosis reveals common and subset-specific DNA methylation aberrancies. Ann Rheum Dis. 2014;8:2014.

30. Lim U, Song MA. Dietary and lifestyle factors of DNA methylation. Method Mol Biol. 2012;863:359-76.

31. Alegría-Torres JA, Baccarelli A, Bollati V. Epigenetics and lifestyle. Epigenomics. 2011;3(3):267-77.

32. Strickland FM, Hewagama A, Wu A, Sawalha AH, Delaney C, Hoeltzel MF, et al. Diet Influences Expression of Autoimmune-Associated Genes and Disease Severity by Epigenetic Mechanisms in a Transgenic Mouse Model of Lupus. Arthritis Rheum. 2013;65(7):1872-81.

33. Higgs BW, Zhu W, Richman L, Fiorentino DF, Greenberg SA, Jallal B, et al. Identification of activated cytokine pathways in the blood of systemic lupus erythematosus, myositis, rheumatoid arthritis, and scleroderma patients. Int J Rheum Dis. 2012;15(1):25-35.

34. Fernandis AZ, Cherla RP, Ganju RK. Differential regulation of CXCR4-mediated Tcell chemotaxis and mitogen-activated protein kinase activation by the membrane tyrosine phosphatase, CD45. J Biol Chem. 2003;278(11):9536-43.

35. Lal G, Zhang N, van der Touw W, Ding Y, Ju W, Bottinger EP, et al. Epigenetic regulation of Foxp3 expression in regulatory $T$ cells by DNA methylation. J Immunol. 2009;182(1):259-73.

36. Thomas TJ, Meryhew NL, Messner RP. Enhanced binding of lupus sera to the polyamine-induced left-handed z-dna form of polynucleotides. Arthritis Rheum. 1990:33(3):356-65.

37. Adhami E. Calculating the etiology of systemic lupus erythematosus. Med Hypotheses. 2004;62(2):237-46.

38. Kano Y, Soda K, Konishi F. Suppression of LFA-1 Expression by Spermine Is Associated with Enhanced Methylation of ITGAL, the LFA-1 Promoter Area. PLoS One. 2013;8(2):e56056.

39. Dong R, Zhao R, Zheng S, Zheng Y, Xiong S, Chu Y. Abnormal DNA methylation of ITGAL (CD11a) in CD4+ T cells from infants with biliary atresia. Biochem Biophysic Res Comm. 2012;417(3):986-90.

40. Veraldi KL, Hsu E, Feghali-Bostwick CA. Pathogenesis of pulmonary fibrosis in systemic sclerosis: lessons from interstitial lung disease. Curr Rheumatol Rep. 2010;12(1):19-25.

41. Ke LY, Chang LL, Liu CC, Hung YH, Lin CH, Li RN, et al. Suppressor of cytokine signaling 1 gene expression and polymorphisms in systemic lupus erythematosus. Lupus. 2010;19(6):696-702.

42. Wang Y, Fan PS, Kahaleh B. Association between enhanced type I collagen expression and epigenetic repression of the FLI1 gene in scleroderma fibroblasts. Arthritis Rheum. 2006;54(7):2271-9.

43. Li Y, Luo H, Liu T, Zacksenhaus E, Ben-David Y. The ets transcription factor Fli-1 in development, cancer and disease. Oncogene. 2015;34(16):2022-203.

44. Svenson JL, Nowling TK. Altered Fli1 regulation and expression in lupus T cells and effects on T cell function. Arthritis Rheum. 2009;60(10):1093.

45. Chong MM, Chen Y, Darwiche R, Dudek NL, Irawaty W, Santamaria P, et al. Suppressor of cytokine signaling-1 overexpression protects pancreatic $\beta$ cells from CD8+ T cell-mediated autoimmune destruction. J Immunol. 2004;172(9):5714-21.

46. Strickland FM, Richardson BC. Epigenetics in human autoimmunity: (Epigenetics in autoimmunity-DNA methylation in systemic lupus erythematosus and beyond). Autoimmunity. 2008; 41(4), 278-286.

47. Kaneto H, Sasaki S, Yamamoto H, Itoh F, Toyota M, Suzuki H, et al. Detection of hypermethylation of the p16(INK4A) gene promoter in chronic hepatitis and cirrhosis associated with hepatitis B or C virus. Gut. 2001;48(3):372-7.

48. Romagosa C, Simonetti S, López-Vicente L, Mazo A, Lleonart ME, Castellvi J, et al. p16Ink4a overexpression in cancer: a tumor suppressor gene associated with senescence and high-grade tumors. Oncogene. 2011;30(18):2087-97.

49. Ivanova TA, Golovina DA, Zavalishina LE, Volgareva GM, Katargin AN, Andreeva $Y$, et al. Up-regulation of expression and lack of 5' CpG island hypermethylation of p16 INK4a in HPV-positive cervical carcinomas. BMC Cancer. 2007;7:47.

50. Gu Z, Cao X, Jiang J, Li L, Da Z, Liu H, et al. Upregulation of p16INK4A promotes cellular senescence of bone marrow-derived mesenchymal stem cells from systemic lupus erythematosus patients. Cell Signal. 2012;24(12):2307-14. 
51. Liu CC, Ou TT, Wu CC, Li RN, Lin YC, Lin CH, et al. Global DNA methylation, DNMT1, and MBD2 in patients with systemic lupus erythematosus. Lupus. 2011;20(2):131-6.

52. Zhu X, Liang J, Li F, Yang Y, Xiang L, Xu J. Analysis of associations between the patterns of global DNA hypomethylation and expression of DNA methyltransferase in patients with systemic lupus erythematosus. Int J Dermatol. 2011;50(6):697-704.

53. Kanda $M$, Nomoto $S$, Okamura $Y$, Nishikawa $Y$, Sugimoto $H$, Kanazumi N, et al. Detection of metallothionein $1 \mathrm{G}$ as a methylated tumor suppressor gene in human hepatocellular carcinoma using a novel method of double combination array analysis. Int J Oncol. 2009:35(3):477-83.

54. Robert MF, Morin S, Beaulieu N, Gauthier F, Chute IC, Barsalou A, et al. DNMT1 is required to maintain CpG methylation and aberrant gene silencing in human cancer cells. Nat Genet. 2002;33:61-5.

55. Wiley KL, Treadwell E, Manigaba K, Word B, Lyn-Cook BD. Ethnic differences in DNA methyltransferases expression in patients with systemic lupus erythematosus. J Clin Immunol. 2013;33(2):342-8.

56. Kozłowska A, Hrycaj P, Łącki JK, Jagodziński PP. Perforin level in CD4+ T cells from patients with systemic lupus erythematosus. Rheumatol Int. 2010;30(12):1627-33.

57. Golder V, Connelly K, Staples M, Morand E, Hoi A. Association of Asian ethnicity with disease activity in SLE: an observational study from the Monash Lupus Clinic. Lupus. 2013;22(13):1425-30.

58. Hughes T, Sawalha A. The role of epigenetic variation in the pathogenesis of systemic lupus erythematosus. Arthritis Res Ther. 2011;13(5):245

59. Kehrmann J, Tatura R, Zeschnigk M, Probst-Kepper M, Geffers R, Steinmann J, et al. Impact of 5-aza-2'-deoxycytidine and epigallocatechin-3-gallate for induction of human regulatory T cells. Immunology. 2014;142(3):384-95.

60. Hagemann S, Kuck D, Stresemann C, Prinz F, Brueckner B, Mund C, et al. Antiproliferative effects of DNA methyltransferase 3B depletion Are Not associated with DNA demethylation. PLoS One. 2012;7(5):e36125.

61. Nyce J, Liu L, Jones PA. Variable effects of DNA-synthesis inhibitors upon DNA methylation in mammalian cells. Nucleic Acids Res. 1986;14(10):4353-67.

62. Wan ES, Qiu W, Baccarelli A, Carey VJ, Bacherman H, Rennard SI, et al. Systemic steroid exposure is associated with differential methylation in chronic obstructive pulmonary disease. Am J Respir Crit Care Med. 2012:186(12):1248-55.

63. Oaks Z, Perl A. Metabolic control of the epigenome in systemic lupus erythematosus. Autoimmunity. 2014:47(4):256-64.

64. Hoogen F, Khanna D, Fransen J, Johnson SR, Baron M, Tyndall A, et al. 2013 classification criteria for systemic sclerosis: an American college of rheumatology/European league against rheumatism collaborative initiative. Arthritis Rheum. 2013;65(11):2737-47.

65. Gladman D, Goldsmith C, Urowitz M, Bacon P, Fortin P, Ginzler E, et al. The systemic lupus international collaborating clinics/American college of rheumatology (SLICC/ACR) damage index for systemic lupus erythematosus international comparison. J Rheumatol. 2000;27(2):373-6.

66. Zielske SP, Epigenetic DNA. Methylation in radiation biology: on the field or on the sidelines? J Cell Biochem. 2015;116(2):212-7.

\section{Submit your next manuscript to BioMed Central and take full advantage of:}

- Convenient online submission

- Thorough peer review

- No space constraints or color figure charges

- Immediate publication on acceptance

- Inclusion in PubMed, CAS, Scopus and Google Scholar

- Research which is freely available for redistribution

Submit your manuscript at www.biomedcentral.com/submit 